\title{
As Emergências Ambientais no Paraná $e$ as Intersecções com o Sistema Estadual de Proteção e Defesa Civil
}

\author{
Eduardo Gomes Pinheiro \\ Pontifícia Universidade Católica do Paraná - Curitiba - Paraná - Brasil \\ Larissa Maria da Silva Ferentz \\ Pontifícia Universidade Católica do Paraná - Curitiba - Paraná - Brasil \\ Murilo Noli da Fonseca \\ Pontifícia Universidade Católica do Paraná - Curitiba - Paraná - Brasil
}

\section{Resumo}

As emergências ambientais costumam afetar diretamente regiões urbanizadas ou o seu entorno, configurando-se como desastres urbanos. Desastres são provenientes de eventos extremos, sejam de origem natural ou de origem tecnológica, os quais resultam em diversos impactos negativos para as cidades. Estes fatores são consequência da falta de preparação de seus gestores e comunidades para o enfrentamento destas situações, além de uma cadeia de falhas desde o planejamento, legislação e fiscalizações ineficientes. Dessa forma, faz-se necessária a análise da organização estrutural dos órgãos públicos para atuar de forma a mitigar esses eventos ou seus efeitos. Nessa linha, encontra-se não um órgão apenas, mas um sistema chamado Proteção e Defesa Civil. O Estado do Paraná, possuidor de um histórico relevante em termos de emergências ambientais, encontra, na sua defesa civil, um núcleo agregador de instituições para tratar o tema. Este artigo se dedica a analisar essa estrutura, suas potencialidades e apresenta alternativas para o aprimoramento voltado à efetividade dos recursos existentes e disponíveis.

Palavras-chave: Emergências ambientais. Proteção e defesa civil. Desastres ambientais. Desastres tecnológicos.

The Environmental Emergencies in Paraná and the Intersections with the State System of Protection and Civil Defense

\begin{abstract}
Environmental emergencies usually affect urbanized regions or their surroundings, becoming urban disasters. Disasters come from extreme events, whether of natural or technological origin, which result in a number of negative impacts on cities. These factors are consequence of the lack of preparation of their managers and communities to face these situations, besides a chain of failures from inefficient planning, legislation and inspections. Thus, it is necessary to analyze the structural organization of public bodies to act in order to
\end{abstract}


mitigate these events or their effects. In this line, there is not only an organ, but a system called Protection and Civil Defense. The State of Paraná, which has a relevant history in terms of environmental emergencies, finds in it civil defense an aggregating nucleus of institutions to deal with this issue. This article is dedicated to analyzing this structure, its potential and presents alternatives for the improvement aimed at the effectiveness of existing and available resources.

Keywords: Environmental emergencies. Protection and civil defense. Environmental disasters. Technological disasters.

\section{Las emergencias ambientales en Paraná y las Intersecciones con el Estado del Estado de Protección y Defensa Civil}

\section{Resumen}

Las emergencias de emergencias urbanas, especialmente urbanizadas, o sus alrededores, plantean urban desastres. Los desastres proceden de eventos extremos, ya sean de origen natural o de origen tecnológico, que resultan en diversos impactos negativos para las ciudades. Estos factores son el resultado de la falta de preparación de sus gestores y comunidades para el enfrentamiento de estas situaciones, además de una cadena de fallas desde la planificación, la legislación y los controles ineficientes. Por lo tanto, es necesario analizar la organización organizativa de los organismos públicos para actuar para atenuar estos eventos o sus efectos. En esta línea, no es sólo un grupo, sino un sistema llamado Protección y Defensa Civil. El Estado de Paraná, que tiene una historia relevante en términos de emergencias emergentes, que se encuentran en la civil de defensa de la agregación de los nucleos de las culturas a este problema. Este artículo se ocupa de esta estructura, su potencial y presenta alternativas para las mejoras de rendimiento en la eficacia de los recursos existentes y disponibles.

Palabras clave: Environmental emergencies. Protección y defensa civil. Ambiental desastres. Technological desastres.

\section{Introdução}

As emergências ambientais fazem parte do cenário urbano, são dele uma consequência. No entanto, só passaram a ter destaque na mídia e nas produções científicas no Brasil a partir da década de 1970 (ULTRAMARI et al, 2008). Suas origens partem da vulnerabilidade e os desdobramentos exigem do poder público e da sociedade ações imediatas, eficazes e integradas. Nessas emergências existe, assim como nos desastres, um momento denominado de "normalidade" e outro, conhecido como "anormalidade" (PINHEIRO, 2008). Ao primeiro, encerram-se as ações preventivas e preparatórias; o segundo, por sua vez, abrange a resposta e a recuperação.

Os desastres podem ser considerados como eventos que geralmente afetam vastas áreas, dificultando o acesso às áreas impactadas, causando o colapso de linhas vitais, como as de comunicações, por exemplo, e excedendo a capacidade de resposta dos órgãos convencionais, exigindo coordenação externa para o seu gerenciamento (ARAUJO, 2009). Portanto, as emergências ambientais podem ser consideradas, normalmente pelas suas dimensões e gravidade, como desastres. Neste artigo, emprega-se o termo "desastres" para se referir às emergências ambientais, inclusive porque a presente análise baseia-se no Sistema de Proteção e 
Defesa Civil ${ }^{1}$, que gerencia eventos que extrapolam a capacidade inicial de atendimento dos demais órgãos envolvidos.

O Estado do Paraná, em seu histórico, especialmente no início dos anos 2000, apresenta várias emergências ambientais responsáveis pela sua inclusão no rol dos cenários trágicos dessa modalidade de desastre (PARANÁ, 2008). Por exemplo, pode-se destacar o vazamento de óleo da Refinaria Getúlio Vargas (REPAR), ocorrido em 2000, em Araucária; do oleoduto OLAPA, em 2001, em Morretes; e do Navio Vicuña, em 2004, em Paranaguá Entretanto, não apenas as emergências ambientais com alto grau de impacto merecem esse destaque. Quase que diariamente acidentes de pequena monta impõem ao ambiente diversos vazamentos de produtos perigosos, resultando em poluição atmosférica, contaminação de solo, destruição de fauna e flora, colocando em risco também a saúde das pessoas, além de outros impactos.

Admitindo-se que os acidentes ocorrem frequentemente em vários pontos do Estado e que as equipes de emergência dos vários órgãos que compõem esse sistema se revezam, e até se integram nesses atendimentos, há de se analisar a forma como esse sistema se organiza antes, durante e após essas emergências, vislumbrando a possibilidade de contribuir para a melhoria desse processo importante para toda a sociedade e meio ambiente.

Em vários desses casos, as intervenções limitam-se às barreiras impostas pelas ações desarmônicas dos órgãos públicos, notadamente durante as fases onde se emite o Licenciamento Ambiental. É justamente nesse momento que as atividades potencialmente geradoras de emergências ambientais podem ser identificadas e tratadas adequadamente pelo conjunto de órgãos que, posteriormente, poderão ser acionados para os atendimentos.

Baseado nessa circunstância, o objetivo deste artigo é analisar a relação das emergências ambientais com o Sistema Estadual de Proteção e Defesa Civil do Paraná, apontando as possibilidades de aprimoramento das ações antes e durante a ocorrência dessas emergências. Busca-se também analisar este Sistema no que se refere à prevenção e resposta às emergências ambientais no território paranaense, a partir das responsabilidades específicas dos principais órgãos ou instituições que o compõem, e identificar os mecanismos preventivos e de resposta existentes e utilizados nas emergências ambientais quanto às atividades desempenhadas pelos órgãos envolvidos.

\section{Emergências ambientais}

Com o crescimento da demanda, transporte e utilização de produtos químicos no país, as emergências ambientais se tornaram uma preocupação no cenário nacional. Não apenas os riscos relacionados aos processos que necessitam destes produtos em sua fabricação ou funcionamento se tornaram alvo de preocupação, mas também pelos resíduos que são gerados nestas etapas e por aqueles resultantes

\footnotetext{
${ }^{1}$ O Sistema de Proteção e Defesa Civil está regulamentado pela Lei Federal 12.608/12 e possui, dentre os desastres catalogados no país, tipologia dedicada às emergências ambientais, no caso, denominados acidentes com produtos químicos perigosos. A Codificação Brasileira de Desastres COBRADE foi instituída pela Instrução Normativa $\mathrm{n}^{\circ}$ 01, de 24 de agosto de 2012 - Ministério da Integração Nacional.
} 
das próprias indústrias químicas. Estes elementos representam riscos à integridade do meio ambiente e da população humana que estiver exposta a estes produtos durante um acidente (MMA, 2004).

Não obstante, a falta de preparação dos agentes, assim como dos gestores locais quanto a fiscalização e medidas emergenciais no caso de acidentes, potencializa os impactos negativos provenientes destes produtos. É por isto que o Sistema Nacional do Meio Ambiente (SISNAMA) juntamente ao Ministério do Meio Ambiente (MMA), desenvolveram o Plano Nacional de Prevenção, Preparação e Resposta Rápida a Acidentes Ambientais com Produtos Perigosos ( $P_{2} R_{2}$ ), instituído pelo Decreto $n^{\circ} 5.098$ de 2004, com o objetivo de não apenas aprimorar o sistema de preparação e resposta a emergências químicas existentes no País, mas principalmente de buscar mecanismos que previnam a ocorrência de acidentes com produtos perigosos (MMA, 2004).

Tendo em vista a constante preocupação que a contaminação por produtos perigosos causa na saúde da população, assim como pelos impactos ao meio ambiente, o presente Plano promove, por meio de sua estruturação (Tabela 1), a integração entre os diversos setores do governo, entidades públicas e privadas, assim como da sociedade civil, buscando pela redução dos riscos e do aumento da qualidade ambiental. Esta integração permite o compartilhamento das responsabilidades, a fim de resultar em um atendimento mais eficaz em caso de acidentes. Conforme o Ministério do Meio Ambiente (2004, p. 2):

os setores produtivos e de serviços ligados à produção, manipulação, comercialização, armazenamento, transporte, uso, manuseio e destino final de substâncias perigosas terão no Plano um marco referencial para a viabilização de ações comprometidas com a proteção da saúde humana e a qualidade ambiental.

Deste modo, a adoção do P2R2 é de extrema importância para a eficiência do desenvolvimento das cidades, levando em conta o compromisso público e privado para a redução dos riscos dos desastres tecnológicos e para a melhoria contínua dos processos, por meio de metas e programas sistêmicos de prevenção, preparação e resposta a emergências ambientais. 


\section{Tabela 1 - Estruturação do Plano Nacional de Prevenção, Preparação e Resposta} Rápida a Emergências Ambientais com Produtos Químicos Perigosos (P2R2)

\begin{tabular}{|c|c|c|}
\hline Item & Subitem & Descrição \\
\hline \multirow[b]{2}{*}{ Metas } & Prevenção & $\begin{array}{l}\text { Por meio da implantação de sistemas, programas, ações e } \\
\text { iniciativas que visam a inibir ou desmotivar práticas que levem à } \\
\text { ocorrência de acidentes envolvendo produtos químicos perigosos }\end{array}$ \\
\hline & Correção & $\begin{array}{l}\text { Por meio da implementação de sistemas, ações e procedimentos } \\
\text { que visam responder de forma rápida e eficaz às ocorrências de } \\
\text { acidentes, assim como preparar; capacitar recursos humanos } \\
\text { disponíveis nas esferas federais, estaduais e municipais }\end{array}$ \\
\hline \multirow{5}{*}{ Estratégias } & & $\begin{array}{l}\text { Criação e operacionalidade de uma estrutura organizacional } \\
\text { adequada }\end{array}$ \\
\hline & & $\begin{array}{l}\text { Integração dos órgãos e instituições públicas no âmbito municipal, } \\
\text { estadual e federal, para o atendimento de situações emergenciais, } \\
\text { estabelecendo seus respectivos níveis de competência }\end{array}$ \\
\hline & & $\begin{array}{l}\text { Definição das responsabilidades respectivas do poder público e dos } \\
\text { setores privados em casos de acidentes }\end{array}$ \\
\hline & & $\begin{array}{l}\text { Disponibilização de informações entre profissionais que trabalham } \\
\text { nos segmentos públicos, responsáveis pelo controle e } \\
\text { atendimento a emergências, setores privados de produção, } \\
\text { armazenamento, transporte e manipulação de produtos químicos } \\
\text { perigosos }\end{array}$ \\
\hline & & $\begin{array}{l}\text { Otimização de recursos humanos, financeiros e treinamento } \\
\text { contínuo dos profissionais e equipes engajados ao plano, no } \\
\text { sentido de ampliar a capacidade de resposta }\end{array}$ \\
\hline \multirow[t]{3}{*}{ Instrumentos } & $\begin{array}{l}\text { Mapeamento de } \\
\text { áreas de risco }\end{array}$ & $\begin{array}{l}\text { O conhecimento prévio das áreas mais propensas à ocorrência de } \\
\text { acidentes com esses produtos é fundamental aos órgãos públicos, } \\
\text { setor privado e à comunidade de forma a prepará-los tanto para a } \\
\text { ocorrência de acidentes como para seu atendimento, visando } \\
\text { conter ou minimizar os efeitos danosos ao meio ambiente e à } \\
\text { população. } \\
\text { A caracterização dessas áreas baseia-se nas relações entre: } \\
\text { localização e caracterização das atividades potencialmente } \\
\text { impactantes, sítios frágeis ou vulneráveis, histórico de ocorrência } \\
\text { de acidentes ambientais, áreas contaminadas e unidades de } \\
\text { respostas a acidentes }\end{array}$ \\
\hline & $\begin{array}{l}\text { Sistema de } \\
\text { informação }\end{array}$ & $\begin{array}{l}\text { Adotando o modelo do Sistema Nacional de Informação do Meio } \\
\text { Ambiente (Sinima), o Sistema de Informação do P2R2 visa } \\
\text { disponibilizar e atualizar informações ao sistema de atendimento a } \\
\text { emergências e integrar todos os atores distribuídos pelo território } \\
\text { nacional }\end{array}$ \\
\hline & $\begin{array}{l}\text { Plano de ação de } \\
\text { emergência (PAE) }\end{array}$ & $\begin{array}{l}\text { Conjunto de planos de ação previamente elaborados para atender } \\
\text { a ocorrência de acidentes com produtos químicos. } \\
\text { O objetivo é estabelecer estratégias e requisitos mínimos de } \\
\text { planejamento das ações que serão empregadas no atendimento de } \\
\text { situações de emergências entre órgãos e instituições públicas, } \\
\text { privadas e comunidade. }\end{array}$ \\
\hline \multirow{3}{*}{$\begin{array}{l}\text { Mecanismos } \\
\text { financeiros }\end{array}$} & & Prevenção e preparação \\
\hline & & Resposta Rápida \\
\hline & & Remediação de Passivos Ambientais \\
\hline
\end{tabular}

Fonte: MMA, 2018

\section{Sistema Estadual de Proteção e Defesa Civil do Paraná}

Com o aumento de impactos negativos nas cidades provenientes da ocorrência de eventos extremos, as comunidades passaram a exercer uma cultura de proteção e defesa para ajudarem uns aos outros. Esta cultura se estendeu até o início da Segunda Guerra Mundial, quando as primeiras Defesas Civis foram estruturadas 
como uma responsabilidade do governo, frente a incêndios, colapsos de edificações e guerras (Defesa Civil PR, 2018).

No Brasil, a Defesa Civil está instituída pela Lei $\mathrm{n}^{\circ} 12.608$ de 2012, sendo denominada como Sistema Nacional de Proteção e Defesa Civil (SINPDEC). A coordenação das ações em todo o território nacional é realizada pelo órgão central do SINPDEC: a Secretaria Nacional de Proteção e Defesa Civil (SEDEC). O objetivo deste órgão é a redução do risco de desastres, por meio de ações de prevenção, mitigação, preparação, resposta e recuperação que abrangem os três níveis de governo federal, estadual e municipal, além da sociedade civil (MIN, 2016).

No estado do Paraná, a Defesa Civil foi criada em 1972, pelo Decreto Estadual $n^{\circ}$ 3.002, passando a Coordenadoria Estadual de Defesa Civil para o âmbito da Casa Militar em 1992, conforme Lei $n^{\circ}$ 9.943. No ano após a instituição da Lei Nacional $n^{\circ}$ 12.608 de 2012, foi regulamentado o Sistema Estadual de Proteção e Defesa Civil (SEPDEC) através Decreto Estadual n 9.557 de 2013. Por fim, em 2014 foi instituído o Sistema Paranaense de Informações para a Gestão dos Riscos a Desastres Naturais (SIGRisco), e em 2015, a Lei n 18.519, Política Estadual de Proteção e Defesa Civil. A estruturação atual do Sistema Estadual de Proteção e Defesa Civil pode ser observada na Figura 1.

As ações da Proteção e Defesa Civil do Paraná, visam prevenir ou minimizar os impactos negativos resultantes de eventos extremos, sejam estes naturais ou tecnológicos. Não obstante, tem como deveres atender as populações que foram atingidas por desastres e socorrer aquelas que ainda estão passando por estes eventos, a fim de evitar perdas materiais e humanas. Estas ações são possíveis com a participação de toda a comunidade na adoção de medidas preventivas, de preparação das pessoas, resposta eficiente e rápida recuperação local (Defesa Civil $P R, 2018)$.

\section{Figura 1 - Sistema Estadual de Proteção e Defesa Civil}

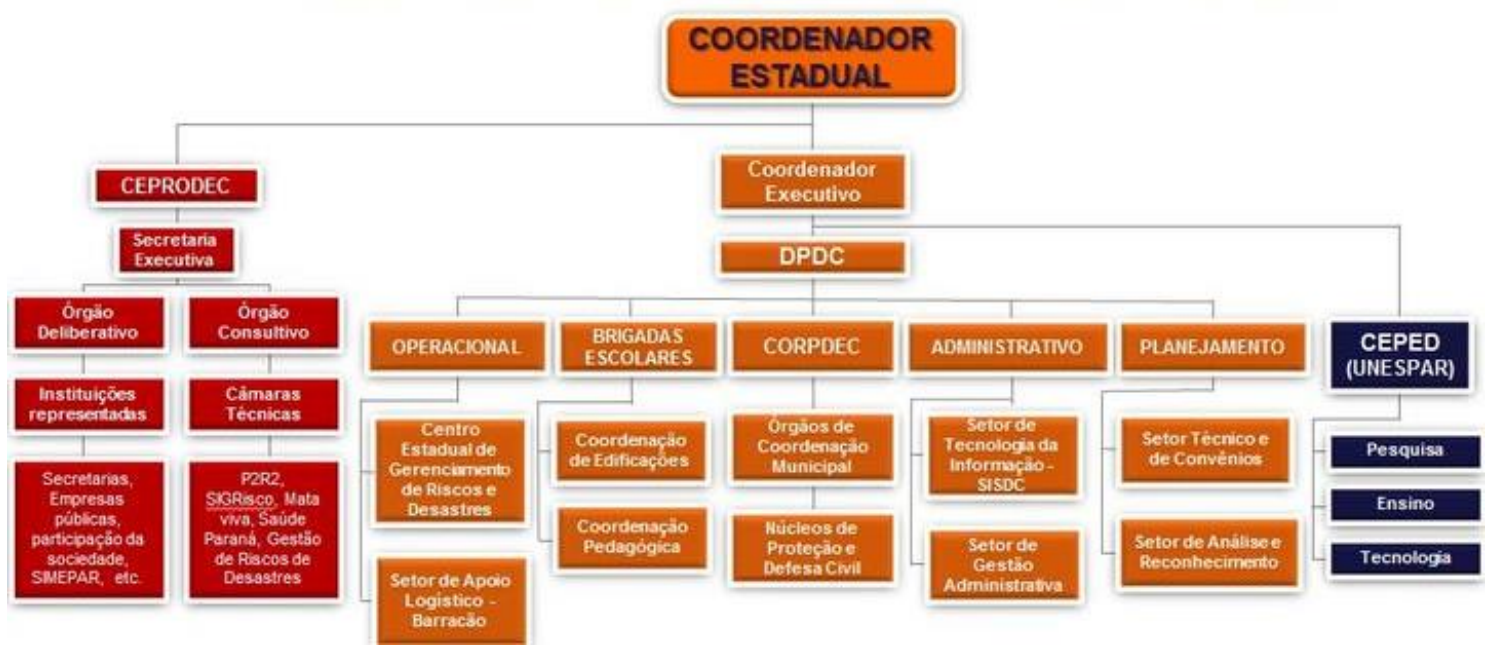

Fonte: Defesa Civil PR, 2018.

\section{Metodologia}


Como forma de aperfeiçoar as informações, foi realizado um levantamento quantitativo dos registros históricos dos acidentes que se caracterizam emergências ambientais no Estado do Paraná e em documentos disponibilizados pela Coordenadoria Estadual de Proteção e Defesa Civil (CEPDEC/PR). Adotou-se o recorte temporal compreendido entre 1980 e 2017 para pautar a pesquisa devido à existência de subsídios adequados para as comparações realizadas entre os órgãos que possuem dados disponíveis.

A pesquisa também teve como parâmetro bibliográfico a utilização das legislações específicas e manuais de defesa civil publicados no país e, especificamente, no Paraná. Além do mais, procurou-se associar ao contraponto oriundo da área ambiental, baseando-se nas informações contidas nos sítios oficias desses órgãos, tanto na esfera estadual, quando na federal. Por fim, a base legal que apoia não apenas a defesa civil enquanto sistema, mas o próprio SISNAMA, foi estudada, resultando na seleção dos principais pontos aplicáveis a este estudo, cujo resultado se volta para a busca de um aprimoramento no trato preventivo e de resposta às emergências ambientais.

Após esse levantamento, e havendo a localização de legislação (leis, decretos) e publicações específicas relacionadas ao tema, passou-se a realizar a análise qualitativa desse conjunto, procurando respostas para os objetivos específicos determinados no planejamento da pesquisa. Tais informações subsidiaram a constituição de dois modelos analíticos: um referente às medidas preventivas e outro, consequentemente, voltado à resposta a essas emergências. Sendo assim, torna-se possível perceber como o sistema se organiza para atuar nas duas fases propostas como objetivo desta pesquisa.

\section{As Emergências Ambientais no Estado do Paraná}

\subsection{Panorama das Emergências e sua Percepções}

As emergências ambientais, devido às costumeiras proporções que tomam, caracterizam-se pela necessidade de mobilização de mais de um órgão público para que se possa dar conta do seu atendimento. No entanto, a etapa da "resposta" não é, necessariamente, a mais importante. Os momentos que antecedem a deflagração de uma emergência são aqueles nos quais é possível evitar que ela aconteça ou, até mesmo, reduzir os efeitos que a sucederão, devendo ser adotadas ações preventivas, mitigatórias e preparatórias efetivas.

No Paraná, as emergências ambientais totalizam 1.332 ocorrências entre 1980 e 2017 (CEPDEC/PR, 2018), dos quais cinco resultaram na decretação de Situação de Emergência (SE). Tais eventos atingiram 201 municípios, sobretudo Curitiba, Paranaguá, Guaratuba, São José dos Pinhais e Ponta Grossa, com 115, 72, 71, 50 e 49 registros, respectivamente. $E$ afetaram 662.852 pessoas, dos quais 1.545 foram desalojadas, 372 desabrigadas, 583 feridas e 205 mortas (CEPDEC/PR, 2018). Por outro lado, considerando o incêndio em vegetação como uma emergência ambiental - e conceitualmente é plenamente possível - apenas os atendimentos realizados pelo Corpo de Bombeiros perfazem outras 6.863 emergências entre 2017-2018 (CBP, 2018). 
Dos acidentes ambientais envolvendo produtos perigosos registrados nesse período há o predomínio daqueles relacionados ao transporte de produtos perigosos no modal rodoviário, ou seja, acidentes com caminhões, que perfazem mais de $65 \%$ do total de ocorrências. Sendo assim, comprova-se a necessidade de existir uma política preventiva integrada e direcionada para esses tipos de acidentes. Não se pode confundir, no entanto, a quantidade de acidentes com a intensidade e magnitude dos danos e prejuízos. Os acidentes no modal rodoviário ganham em quantidade, mas não chegam a superar aqueles envolvendo o manuseio e a armazenagem desses produtos.

A distribuição anual no período desses atendimentos apurado é demonstrada no Gráfico 1. Ela permite perceber que existe oscilação entre as quantidades e não uma distribuição regular desses eventos. Importante ressaltar que as coordenadorias de proteção e defesa civil e a de acidentes ambientais, erroneamente, não incluem os incêndios em vegetação no rol desse tipo de acidente. Caso o fossem, os números seriam mais importantes.

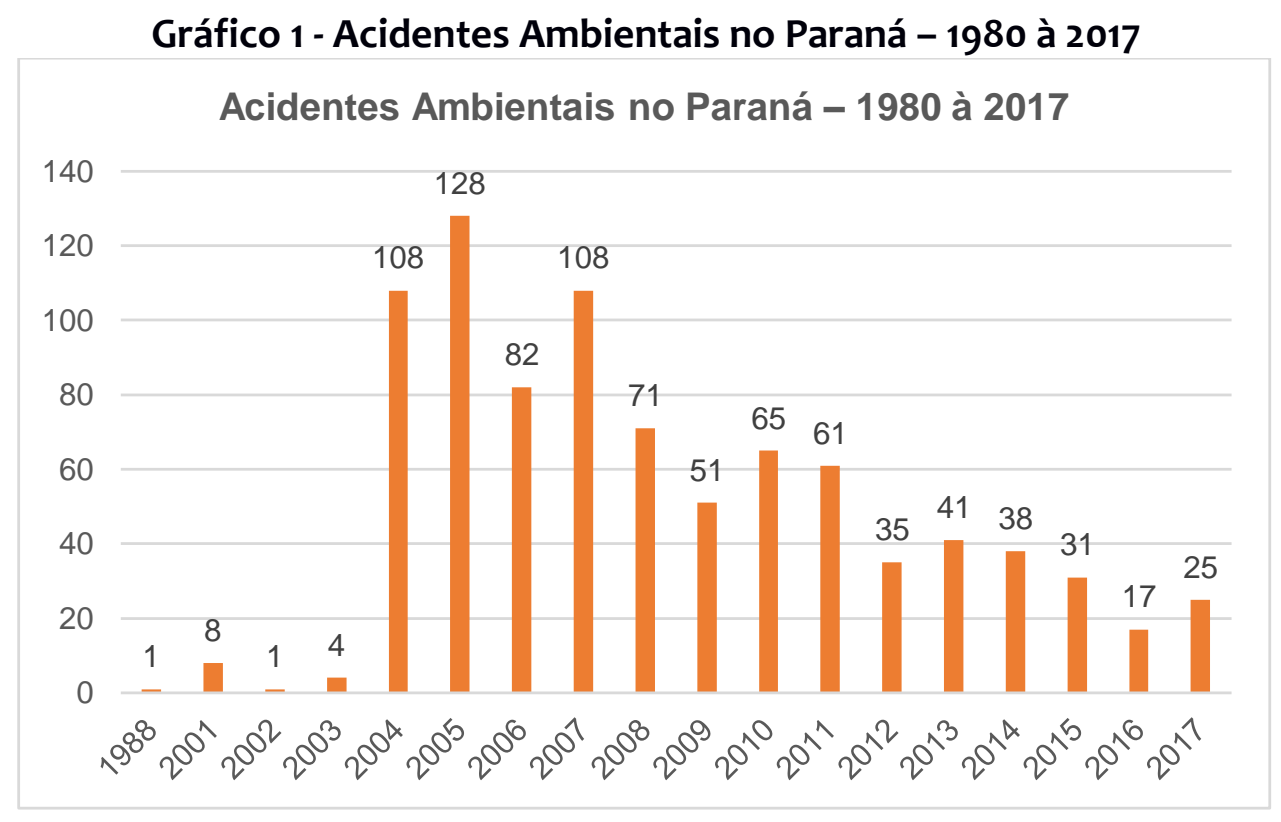

Fonte: CEPDEC/PR, 2018

Os acidentes que desencadeiam as emergências ambientais são fatos cujas consequências abrangem diversas áreas, em caráter simultâneo ou com lapso sequencial de tempo. O hodierno sistema de atendimento se apresenta como um conjunto de órgãos que são acionados a partir do primeiro que chega ao local do acidente, como medida proveniente de um acordo previsto no Plano Estadual de Produtos Perigosos, conforme segue:

o primeiro órgão ao receber o aviso quase sempre varia de acordo com o tipo de acidente. Há de se convir que, até mesmo em relação ao transporte, apenas a variação do modal implica em acionamentos distintos. Dessa forma, convenciona-se, para a eficácia do funcionamento deste Procedimento Operacional Padrão e do Plano de Prevenção e Resposta a Acidentes com Produtos Perigosos, que o primeiro órgão a ser avisado sobre um acidente envolvendo produtos perigosos, mesmo que não confirmado (principalmente em locais mais distantes), deverá acionar o 
Sistema de Defesa Civil (...) Após o repasse da informação sobre o acidente, a CEDEC e a COREDEC ficam encarregadas de acionar os demais órgãos no menor tempo possível (DEFESA CIVIL, 2007, p.58).

O que se compreende é que existe uma previsão para que os órgãos se integrem no momento da resposta (Figura 2), no entanto essa integração restringese ao aspecto escrito e resulta na desconexão prática entre os órgãos, ocasionando intensificação e agravamento dos danos e prejuízos.

\section{Figura 2 - Variações de ponto de vista sobre uma mesma emergência ambiental}

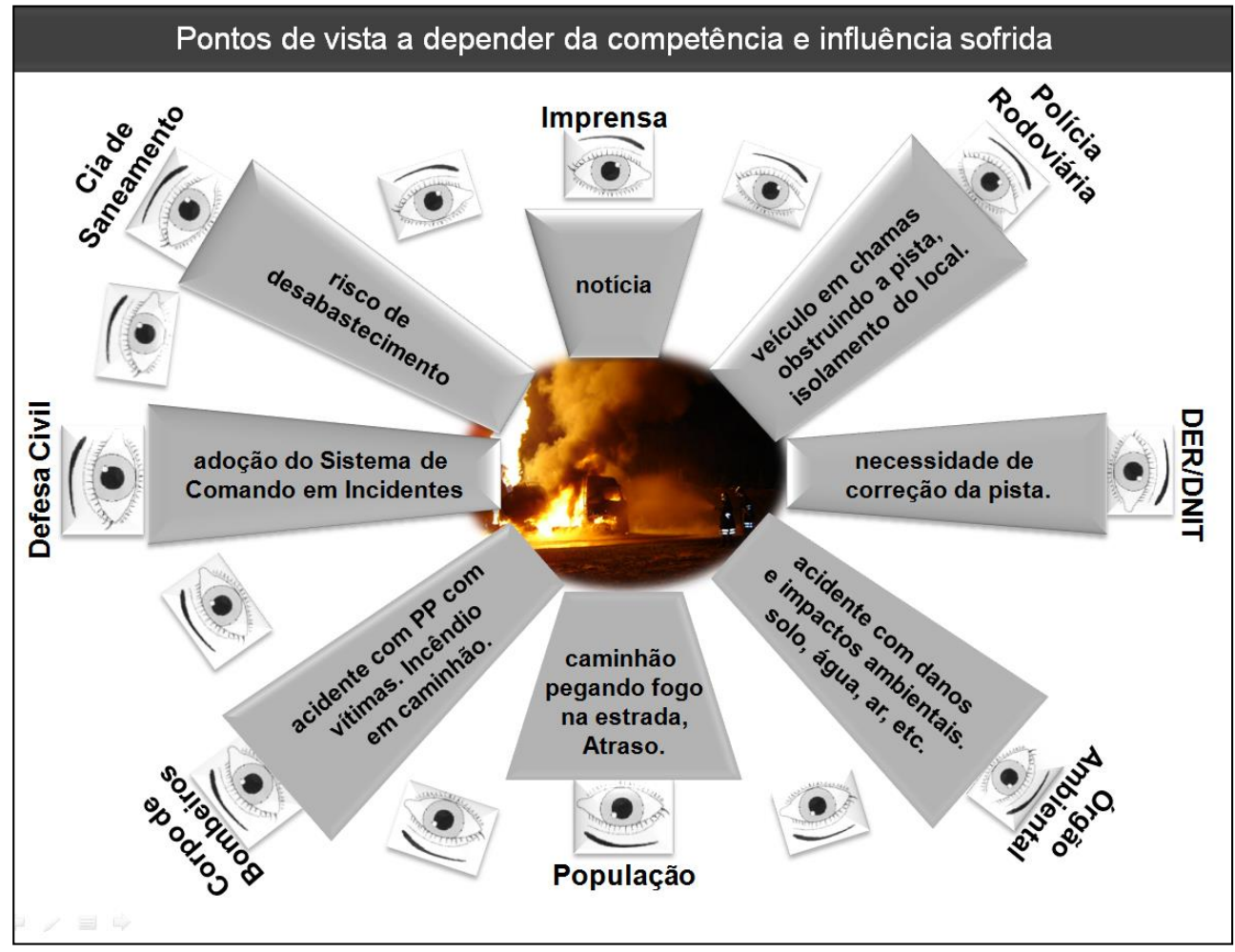

Fonte: elaboração própria.

Essa circunstância se verifica na percepção de que os principais órgãos envolvidos com as atividades de resposta estão ausentes na maior parcela do território paranaense. Dessa forma, o atendimento, que reduziria os impactos posteriormente ao surgimento e a comunicação da emergência, não possui eficácia, tendo em vista que consente a evolução da variável 'tempo'.

\subsection{Análise Documental}

O repertório legislativo, embora recente, é razoavelmente significativo no tratamento ao tema. O Decreto $n^{\circ} 5.098 / 2004$, dispõe sobre a criação do Plano Nacional de Prevenção, Preparação e Resposta Rápida a Emergências Ambientais com Produtos Químicos Perigosos - P2R2. Essa tratativa nacional não fora reproduzida com este nome e formato no Paraná, optando-se pela manutenção do Decreto $n^{\circ} 4.299 / 2001$, o qual criou o Programa do Transporte, Manuseio e Armazenagem de Produtos Perigosos no Estado do Paraná. 
Mas, o Decreto $n^{\circ} 7.117 / 2013$, que criou a Comissão Estadual de Prevenção, Preparação e Resposta Rápida às Emergências Ambientais que envolvam Produtos Químicos Perigosos - CEP2R2, revogou o Decreto nº 4.299/2001. Nesta comissão há o envolvimento de diversas instituições e órgãos e através dela já foram organizados o Plano de Atendimento a Emergências com Produtos Perigosos no Modal Rodoviário e estabelecidas as diretrizes para a fiscalização rodoviária e em empresas que possuam relação com produtos perigosos (CEPED-PR/FUNESPAR, 2016). Apesar disso, os autores advertem que um dos principais problemas que afetam a gestão de riscos de desastres no Estado do Paraná é a falta de implementação do P2R2.

Na mesma toada, o tratamento aos incêndios florestais - que também se caracterizam como emergências ambientais - foi instituído pelo Decreto $\mathrm{n}^{\circ}$ 4.223/1998, tratando sobre o Plano Estadual de Prevenção a Incêndios Florestais. Recentemente, foi criado o Programa de Prevenção de Incêndios na Natureza PREVINA, por meio do Decreto $n^{\circ} 10.859 / 2018$. Ele visa promover medidas de prevenção e resposta nas Unidades de Conservação Estaduais, no que se refere aos incidentes envolvendo Incêndios Florestais (art. $2^{\circ}$ ).

Também, chama a atenção a sigla P2R2, oficializada pelo Decreto $\mathrm{n}^{\circ}$ 5.098/2004, comumente confundida com a antiga forma de abreviar as ações globais de defesa civil (prevenção, preparação, resposta e reconstrução), posteriormente recebendo a adição da mitigação, passando a compreender cinco ações (Figura 3), elaborada a partir da Lei Federal nº 12.608/2012.

Figura 3 - Ações de Proteção e Defesa Civil

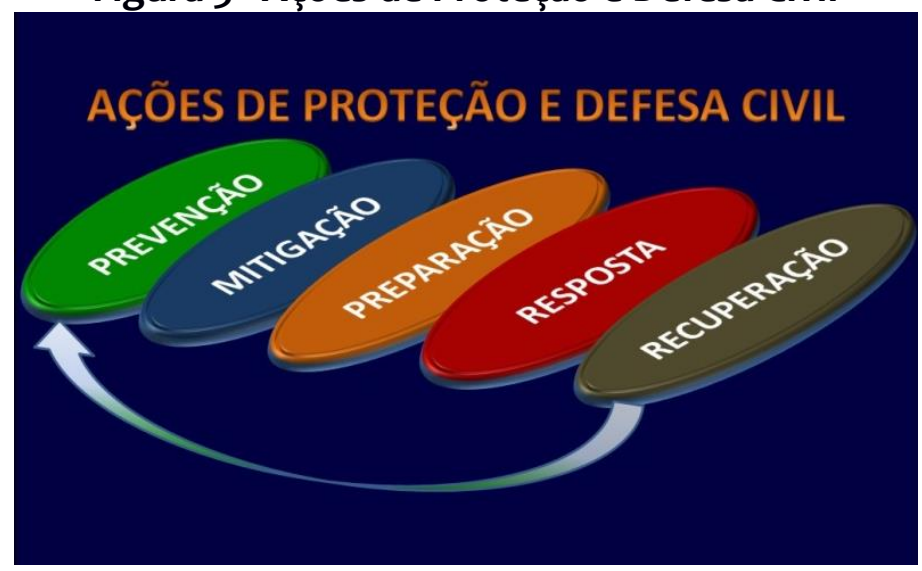

Fonte: elaboração própria.

A comparação entre o estabelecimento dessas ações na Política Nacional de Proteção e Defesa Civil e os termos que integram o título do programa atrelado aos produtos químicos perigosos, instituídos pelo decreto federal especificado, não se tratam de coincidência, mas têm a intenção de ordenar ações antes e após a ocorrência desses eventos, durante os períodos de normalidade e anormalidade (PINHEIRO, 2008). É justamente essa divisão, abrangendo o antes e o após as emergências ambientais, a balizadora desta análise, que propõe a busca pelos mecanismos preventivos e, posteriormente, a previsão de ações integrantes da resposta às emergências ambientais.

\subsection{Mecanismos Preventivos}


A prevenção consiste na possibilidade de impedir que o evento aconteça ou, pelo menos, de reduzir sua intensidade e, logo, os impactos. A doutrina de proteção e defesa civil expõe o que seria a prevenção voltada aos desastres:

\begin{abstract}
conjunto de ações destinadas a reduzir a ocorrência e a intensidade de desastres naturais ou humanos, através da avaliação e redução das ameaças e/ou vulnerabilidades, minimizando os prejuízos socioeconômicos e os danos humanos, materiais e ambientais. Implica a formulação e implantação de políticas e de programas, com a finalidade de prevenir ou minimizar os efeitos de desastres. A prevenção compreende: a Avaliação e a Redução de Riscos de Desastres, através de medidas estruturais e não-estruturais. Baseia-se em análises de riscos e de vulnerabilidades e inclui também legislação e regulamentação, zoneamento urbano, código de obras, obras públicas e planos diretores municipais (CASTRO, 2003, p.142).
\end{abstract}

Acredita-se que a prevenção esteja atrelada com a percepção de risco, isto é, com a impressão ou juízo intuitivo sobre a natureza e a magnitude de um determinado risco. Percepção sobre a importância ou gravidade de um determinado risco, com base no repertório de conhecimento acumulado durante 0 desenvolvimento cultural de um indivíduo, e sobre o juízo político e moral de sua significação (BRUGGEMAN, 2009). Perceber riscos é um dos pontos de partida para a redução das vulnerabilidades ou para tornar possível a compreensão de que se está em risco iminente diante de certo perigo. Essa abordagem acena para o desenvolvimento da resiliência das comunidades não apenas em relação aos desastres, mas, também, às emergências ambientais.

O Estado do Paraná, quanto às emergências ambientais, possui alguns mecanismos preventivos, dentre os quais se destacam a legislação específica, o Conselho Estadual de Produtos Perigosos e o licenciamento ambiental. Apesar da existência da legislação federal, o Decreto referente ao P2R2, o Paraná manteve o seguimento do contido no Decreto Estadual $n^{\circ} 4299 / 2001$. A rigor, esse decreto representa uma evolução comparando-se à forma restrita como o tema foi tratado até o final da década de 1990, já que o foco legislativo tinha sido desde $1995^{2}$ o transporte rodoviário de produtos perigosos.

Contudo, após uma sequência de emergências ambientais envolvendo o modal dutoviário, o manuseio e a armazenagem de produtos químicos perigosos e o modal aquaviário de transporte (PINHEIRO, 2009), há a criação desse decreto com a necessária abrangência, antecipando, além da constituição do Conselho Estadual de Produtos Perigosos, a existência de elaboração de um plano específico para o tema. A edição mais recente do plano, de 2008, faz menção ao Decreto P2R2, ao fundamentar sua elaboração:

\footnotetext{
${ }^{2}$ Remonta-se à década de 90, mais precisamente ao ano de 1995, a primeira iniciativa para se tentar diagnosticar como estava acontecendo o transporte dos produtos perigosos no Paraná. A partir de resoluções do CODESUL - Conselho de Desenvolvimento e Integração Sul - a prioridade consistiu em levantar dados sobre o modal rodoviário - ainda visto em alguns estados como o principal ou, inclusive, único a receber a atenção das autoridades - devido, principalmente, à incidência de acidentes e à visibilidade que tal meio de transporte possui no quotidiano das pessoas (PARANÁ, 2007, p.6).
} 
o Conselho Estadual de Produtos Perigosos tem por objetivo integrar os diversos órgãos públicos competentes sobre o assunto, em cumprimento a uma legislação especialmente desenvolvida para esta finalidade: o Decreto Estadual no 4.299 de 21 de junho de 2001- Programa Estadual de Controle do Transporte, Manuseio e Armazenagem dos Produtos Perigosos no Estado do Paraná, em consonância com o Decreto Federal $n^{\circ}$ 5.098, de 3 de junho de 2004 que cria o Plano Nacional de Prevenção, Preparação e Resposta Rápida a Emergências Ambientais com Produtos Químicos Perigosos - P2R2 (PARANÁ, 2007, p.5).

O Conselho Estadual de Produtos Perigosos, além do aludido plano, possui reuniões periódicas e extensões para as Coordenadorias Regionais de Defesa Civil, resultando na análise dos acidentes, dos procedimentos e na aproximação entre as instituições que possuem relação direta ou indireta com as emergências ambientais e com as suas consequências.

Outro componente preventivo pode ser considerado o licenciamento ambiental. A responsabilidade de realizá-lo, no Estado, cabe ao Instituto Ambiental do Paraná - IAP, caracterizando-se como um procedimento administrativo para verificar a satisfação das condições legais e técnicas, licenciando a localização, instalação, ampliação e a operação de empreendimentos e atividades que utilizam recursos ambientais, consideradas efetiva ou potencialmente poluidoras ou daquelas que possa causar degradação e/ou modificação ambiental, atendendo as disposições legais e regulamentares e as normas técnicas aplicáveis ao caso (IAP, 2018).

Percebe-se que um dos objetivos do licenciamento é o de permitir a intervenção do Estado, por meio do seu órgão ambiental, na instalação e funcionamento das empresas potencialmente poluidoras ou que venham a degradar ou modificar a qualidade ambiental, o que se pode associar a um acidente que culmine na emergência ambiental. Das exigências realizadas às empresas, uma se chama plano de contingência, o qual possui como definição:

\footnotetext{
o planejamento figura como um dos principais instrumentos para tal feito. Ele está inserido na primeira etapa do que seriam as ações preventivas. Mas é importante referenciar que planejar para atender emergências, a partir das hipóteses mais prováveis ou projeções de maior gravidade, são atribuições do planejamento contingencial ou de emergência, conforme reza a doutrina quando define tais planos (PINHEIRO, 2011, p.).
}

Um problema detectado nessa etapa se refere aos planos de contingência que, além de requisitos para o licenciamento, são elementos preparatórios para emergências e desastres, possuem análise restrita ao órgão ambiental - deixando os órgãos emergenciais de poderem interferir no processo realizando observações importantes para a redução do tempo resposta e da integração de órgãos durante o atendimento às emergências.

Outros elementos integrantes da prevenção são os Conselhos Estadual de Produtos Perigosos e o Conselho Mata Viva. Esses conselhos possuem a participação de membros do Conselho de Órgãos Governamentais, instituído pelo Decreto Estadual $n^{\circ} 1343$, de 29 de setembro de 1999. Ao todo, 38 órgãos e instituições o compõem porque possuem algum tipo de relação com as causas ou consequências decorrentes de desastres. Caracteriza-se pela existência de reuniões periódicas e pela 
busca da capacitação integrada, desenvolvimento de mecanismos para fazerem frente a tais eventos. A integração é enfatizada, pois se acredita que ela:

\begin{abstract}
a integração permanente e periódica continua sendo a base sólida para o desenvolvimento das ações preventivas irmanadas, envolvendo todos os diferentes e complementares organismos que compõem o Conselho Estadual de Produtos Perigosos Ela precisa acontecer no momento preventivo e preparatório permitindo um contato prévio que tende a resultar numa harmonização - base para um trabalho com velocidade, qualidade e eficácia no momento da resposta num desastre de qualquer proporção (PARANÁ, 2007, p.8).
\end{abstract}

Fica evidente uma questão antagônica em relação aos conselhos porque, ainda que destaquem a necessidade de integração entre as instituições, um dos reflexos que podem estar contribuindo para a problemática das emergências ambientais é a ausência de participação das instituições na exigência e análise do planejamento contingencial, por exemplo.

\title{
5.4 Mecanismos Preventivos
}

A resposta considera-se abrangente o suficiente para compreender o durante e o imediatamente após a ocorrência da emergência ambiental. Nesse caso, as prescrições contidas nos Planos Estadual de Produtos Perigosos e Mata Viva serão consideradas quanto aos Procedimentos Operacionais Padrão. O Plano Estadual de Produtos Perigosos define tais procedimentos, procurando esclarecer a possibilidade da ocorrência de conflitos com os aqueles previstos intrainstitucionalmente:

Serão estabelecidos Procedimentos Operacionais Padrão - POP para a viabilização dos atendimentos emergenciais envolvendo Produtos Perigosos entre os integrantes dos Níveis de Coordenação, Operacional e Técnico. Tais procedimentos não pretendem substituir aqueles que são próprios de cada instituição, porém, visam a integração entre esses procedimentos particulares, desenhando as ações de Defesa Civil de forma genérica, resultando na integração entre os órgãos durante o atendimento ao acidente (PARANÁ, 2007, p.18).

Esses procedimentos possuem a finalidade de regular e organizar a integração dos órgãos e instituições durante esses atendimentos. A Figura 4 demonstra o fluxo estabelecido para que as instituições que são acionadas pela população, pois possuem e competência de prestar o serviço de resposta emergencial, onde o primeiro órgão informado recebe a incumbência de disparar a informação sobre a ocorrência logo que ela ingressar como solicitação e for confirmada, para os demais previamente acordados. 
Figura 4 - Fluxograma representativo da resposta a emergências ambientais no Paraná

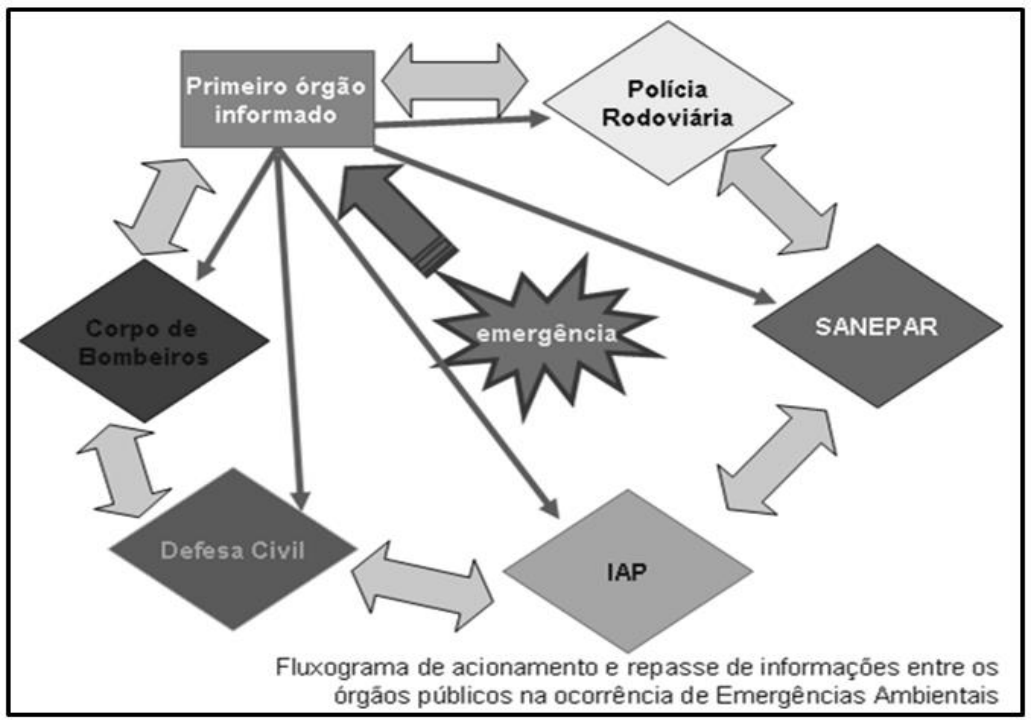

Fonte: elaborado a partir de PARANÁ (2007).

Interessante ressaltar que a medida aparenta prezar pela precaução proporcionando um alinhamento prévio entre essas instituições de forma que suas ações ocorram não apenas integradas, mas de forma sequencialmente adequada. $\mathrm{Na}$ versão gráfica, a existência do chamado "Primeiro órgãos informado" propende sanar a imprevisibilidade de ingresso do chamado emergencial para um órgão específico. Essa característica varia em função do modal de transporte onde se deflagra a emergência, sua natureza (explosão, incêndio florestal), ou se relacionada a manuseio ou armazenagem.

\section{Intersecções com o Sistema de Proteção e Defesa Civil}

A defesa civil pode ser compreendida como sendo "o conjunto de ações preventivas, de socorro, assistenciais e reconstrutivas, destinadas a evitar ou minimizar os desastres, preservar o moral da população e restabelecer a normalidade social" (BRASIL, 2012). Não obstante, ela também é um sistema do qual participam todos os órgãos e instituições, sendo essencial para o combate de emergências (PINHEIRO, 2011).

\subsection{Possibilidades: aprimoramento preventivo}

Ainda que existam legislações específicas que contribuam na prevenção e resposta de emergências ambientais, foi apresentado anteriormente a dificuldade de atuação dos profissionais de meio ambiente, tendo em vista que os órgãos responsáveis não estão presentes em todos os municípios do estado. Deste modo, é de suma importância a busca pelo envolvimento das esferas governamentais - não só a federal e as estaduais, mas também das municipais -, assim como pela realização de parcerias com organizações não-governamentais, setor privado, instituições acadêmicas e a comunidade, propendendo uma execução compartilhada na busca de resultados efetivos. 
Como exemplo de um sistema de integração, pode-se citar a Redesastre Rede Estadual de Pesquisa, Ensino, Extensão e Inovação Tecnológica, instituída sob o Decreto Estadual no 12445/2014. Esta Rede surgiu com a cooperação de instituições de ensino e pesquisa com o Centro Universitário de Estudos e Pesquisas sobre Desastres (CEPED/PR), tendo como objetivo o desenvolvimento de pesquisas, treinamentos, desenvolvimento tecnológicos e serviços educacionais voltados à redução de riscos e desastres no Paraná.

Esta integração não só contribui com projetos que visam a prevenção, mitigação e preparação das comunidades face às situações emergenciais, como pode ter responsabilidades técnicas, como o auxílio com a fiscalização - a qual representa um dos processos mais falhos dos órgãos ambientais, tendo em vista a falta de recursos humanos. Além disto, outras vantagens de se trabalhar em rede estão relacionadas às oportunidades de melhoria contínua, já que diferentes atores estarão em contato com os serviços e processos ofertados.

A partir destes fatores tem-se o maior comprometimento de servidores com as políticas, metas e programas de abordagem sistemática, a fim de obter o avanço na prevenção e combate a esses eventos; tem-se a avaliação contínua do desempenho destas políticas, objetivos e metas previstos; assim como a formação e capacitação dos servidores dos órgãos ambientais e instituições envolvidas com a temática da redução dos riscos de desastres.

Além do mais, é imprescindível ressaltar que os municípios paranaenses já possuem equipes e coordenadores de proteção e defesa civil, os quais podem realizar ações preventivas com suas comunidades, fiscalizações locais autorizadas pelos órgãos e o desenvolvimento de planos preventivos juntamente aos bombeiros militares de seus municípios. No entanto, para que isto ocorra, é fundamental a existência de uma reorganização estrutural dos órgãos públicos, de tal modo que seja possível atuar de forma integrada, pela busca da mitigação dos impactos causados por estes eventos.

\subsection{Possibilidades: aprimoramento responsivo}

Além das medidas preventivas, os coordenadores municipais de proteção e defesa civil também podem realizar os primeiros acionamentos e chamados para atendimento na ocorrência de emergências. Não obstante, os bombeiros militares que estiverem nas proximidades destas ocorrências, podem ser peças chave para a autuação e primeiros atendimentos. Hodiernamente, somente os órgãos ambientais e a Força Verde podem realizar este tipo de ação, porém, ocorrências de pequena monta acabam não se caracterizando como passivos ambientais, pois quando os responsáveis conseguem chegar até o local, a autuação não é mais "em flagrante".

Por essa razão, a equipe técnica e o coordenador municipal de Proteção e Defesa Civil são elementos essenciais para resolver esta problemática. Os bombeiros podem ser responsáveis por realizar o registro fotográfico, assim como da autuação ambiental imediata, não precisando esperar o órgão ambiental chegar, e nem correr o risco de que o passivo seja agravado ou minimizado por fatores de dispersão, inocentando o infrator pelo tempo de espera destes órgãos. 


\section{Considerações finais}

Os incêndios florestais e acidentes com produtos químicos perigosos são classificados como emergências ambientais, mas o país e o estado não os tratam em conjunto, separando os fóruns e a legislação que se dedica a tratá-los. Dessa maneira, há uma alienação do real impacto produzido por essas emergências, sobretudo a inexistência da necessária transformação em valores que traduzam o impacto desses eventos sobre o desenvolvimento do território do Estado do Paraná.

O licenciamento ambiental ocorre desassociado de dados e informações determinantes para influenciar na concessão de atividades potencialmente poluidoras sejam instaladas. Sem isso, o Estado tende a permitir que sejam geradas vulnerabilidades - pré-requisitos para a ocorrência de emergências ambientais qualificadas como desastres. Os planos de contingências, elementos pertencentes à preparação para emergências e desastres não possuem análise técnica apropriada por falta de recursos humanos.

Desta forma, a (re)estruturação deste sistema se faz necessária, a fim de se buscar pela efetividade dos atendimentos. Para isto, a integração com o Sistema de Proteção e Defesa Civil, além dos diferentes atores da sociedade, pode ser uma das opções mais rápidas e acessíveis de se mudar o quadro existente e fortalecer um sistema mais eficiente e preparado.

\section{REFERÊNCIAS}

ARAUJO, S. B. Administração de Desastres - Conceitos fundamentais. Rio de Janeiro: Sygma, 2009.

BRASIL. Drecreto $\mathbf{n}^{\circ} \mathbf{5 . 0 9 8}$ de 03 de junho de 2004. Dispõe sobre a criação do Plano Nacional de Prevenção, Preparação e Resposta Rápida a Emergências Ambientais com Produtos Químicos Perigosos - P2R2, e dá outras providências. Brasília, 3 de junho de $2004 ; 183^{\circ}$ da Independência e $116^{\circ}$ da República.

. Lei $\mathbf{n}^{\circ} \mathbf{1 2 . 6 0 8}$ de 10 de abril de 2012. Institui a Política Nacional de Proteção e Defesa Civil - PNPDEC; dispõe sobre o Sistema Nacional de Proteção e Defesa Civil SINPDEC e o Conselho Nacional de Proteção e Defesa Civil - CONPDEC; autoriza a criação de sistema de informações e monitoramento de desastres; altera as Leis nos 12.340, de 10 de dezembro de 2010, 10.257, de 10 de julho de 2001, 6.766, de 19 de dezembro de 1979, 8.239, de 4 de outubro de 1991, e 9.394, de 20 de dezembro de 1996; e dá outras providências. Brasília, 10 de abril de 2012.

BRUGGEMANN, F. Percepção de Risco. Florianópolis: Defesa Civil de Santa Catarina, 2009

CASTRO, A. L. C. Manual de Desastres. Volume I. Desastres Naturais. Ministério da Integração Nacional, Secretaria Nacional de Defesa Civil. Brasília, 2003. 174p.

CBP. SYSBM. CORPO DE BOMBEIROS DO PARANÁ, 2018. 
CEPDEC/PR. SISDC - Sistema Informatizado de Defesa Civil: Estatísticas 2009. Coordenadoria Estadual de Defesa Civil do Paraná. Curitiba: 2009.

. BI - Business Intelligence. Coordenadoria Estadual de Defesa Civil do Paraná. Curitiba: 2018.

CEPED-PR, FUNESPAR. Construindo um Estado Resiliente: o modelo paranaense para a gestão do risco de desastres. Org. por PINHEIRO, E.G, PEDROSO, F.F.F. Curitiba: CEPED/FUNESPAR, 2016.156p.il

DEFESA CIVIL PR. Estrutura Estadual. Casa Militar, Coordenadoria Estadual de Proteção e Defesa Civil, 2018.

IAP. Procedimento para o Licenciamento Ambiental. Instituto Ambiental do Paraná, 2018. Disponível em: <http://www.iap.pr.gov.br/pagina-1336.html>. Acesso em: 28 out. 2018.

MIN. Apresentação. Ministério da Integração Nacional, 2016. Disponível em: <http://www.mi.gov.br/web/guest/sedec/apresentacao>. Acesso em: 28 out. 2018.

MMA. Emergências Ambientais. Ministério do Meio Ambiente, 2018. Disponível em: < http://www.mma.gov.br/seguranca-quimica/emergencias-ambientais >. Acesso em: 28 out. 2018.

. Plano Nacional de Prevenção, Preparação e Resposta Rápida a Emergências Ambientais com Produtos Químicos Perigosos - P2R2. Ministério do Meio Ambiente, 2004.

PARANÁ. Conselho Estadual de Produtos Perigosos - Plano Estadual 2007. Paraná: Coordenadoria Estadual de Defesa Civil, 2007.

. Conselho Estadual Mata Viva - Plano Estadual 2007. Paraná: Coordenadoria Estadual de Defesa Civil, 2007.

. Decreto Estadual ${ }^{\circ} \mathbf{3 . 0 0 2}$ de 30 de dezembro de 1972. Implanta e dá normas de funcionamento ao Sistema de Defesa Civil no Estado do Paraná. Curitiba, em 29 de dezembro de $1972,151^{\circ}$ da Independência e $84^{\circ}$ da República.

. Decreto Estadual $\mathbf{n}^{\circ} \mathbf{9 . 5 5 7}$ de 6 de Dezembro de 2013. Institui o Regulamento do Sistema Estadual de Proteção e Defesa Civil - SEPDEC, o Centro de Estudos e Pesquisas sobre Desastres - CEPED e dá outras providências. Curitiba, em 06 de dezembro de $2013,192^{\circ}$ da Independência e $125^{\circ}$ da República.

. Lei $\mathbf{n}^{\circ} \mathbf{9 . 9 4 3}$ de 27 de abril de 1992. Dá nova redação ao art. 17, da Lei nº 8.485, de 03 de junho de 1987 (âmbito de ação da Casa Militar). Palácio do Governo em Curitiba, em 27 de abril de 1992. 
. Lei $\mathbf{n}^{\circ} \mathbf{1 8 . 5 1 9}$ de 24 de julho de 2015. Instituição da Política Estadual de Proteção e Defesa Civil. Palácio do Governo, em 23 de julho de 2015.

PINHEIRO, E. G. Defesa Civil para Prefeitos. Paraná: Imprensa Oficial, 2008.

. O sistema estadual de defesa civil na prevenção e atendimento às emergências ambientais no Paraná. 79 f. Monografia (Especialização em Emergências Ambientais), Pontifícia Universidade Católica do Paraná. Curitiba, 2009.

. Estruturação de fundamentos referenciais para a elaboração do Plano Diretor de Defesa Civil como instrumento de gestão urbana. 158 f. Dissertação de Mestrado (Programa de Pós-Graduação em Gestão Urbana), Pontifícia Universidade Católica do Paraná, Curitiba, 2011.

SILVA, E. L.; MENEZES, E. M. Metodologia da pesquisa e elaboração de dissertação. 4. ed. rev. atual. - Florianópolis: UFSC, 2005.

ULTRAMARI, C.; REZENDE, D. A.; FIRMINO, R. Dos conceitos de acidentes e suas correlações sóciodemográficas: o caso do estado do Paraná. Anais: XVI Encontro Nacional de Estudos Populacionais, ABEP, Caxambu, 2008.

Eduardo Gomes Pinheiro. Doutor e Mestre em Gestão Urbana pela Pontifícia Universidade Católica do Paraná, Bacharel em Segurança Pública - Curso de Formação de Oficiais pela Academia Policial Militar do Guatupê - APMG. Especialista em Emergências Ambientais, em Administração - Segurança Pública, em Metodologia do Ensino Superior e Educação à Distância e em Redução do Risco de Desastre e Desenvolvimento Local Sustentável.. egopinheiro@hotmail.com

Larissa Maria da Silva Ferentz. Doutoranda e Mestra em Gestão Urbana pela Pontifícia Universidade Católica do Paraná, possui especialização em Gestão Ambiental pelo Instituto Souza e graduação em Engenharia Ambiental pela PUCPR. ferentzengenharia@gmail.com

Murilo Noli da Fonseca. Mestrando em Gestão Urbana pela Pontifícia Universidade Católica do Paraná, possui especialização em Gestão Ambiental pelo Instituto Souza e graduação em Geografia (bacharel) pela Universidade Federal do Paraná.murilonoli@gmail.com 

Defesa Civil

Como citar: PINHEIRO, Eduardo Gomes; FERENTZ, Larissa Maria da Silva; FONSECA, Murilo Noli da. As Emergências Ambientais no Paraná e as Intersecções com o Sistema Estadual de Proteção e Defesa Civil. Redes, Santa Cruz do Sul, v. 24, n. 2, p. 81-98, maio 2019. ISSN 1982-6745. Disponível em: https://doi.orq/10.17058/redes.v24i2.12995. 